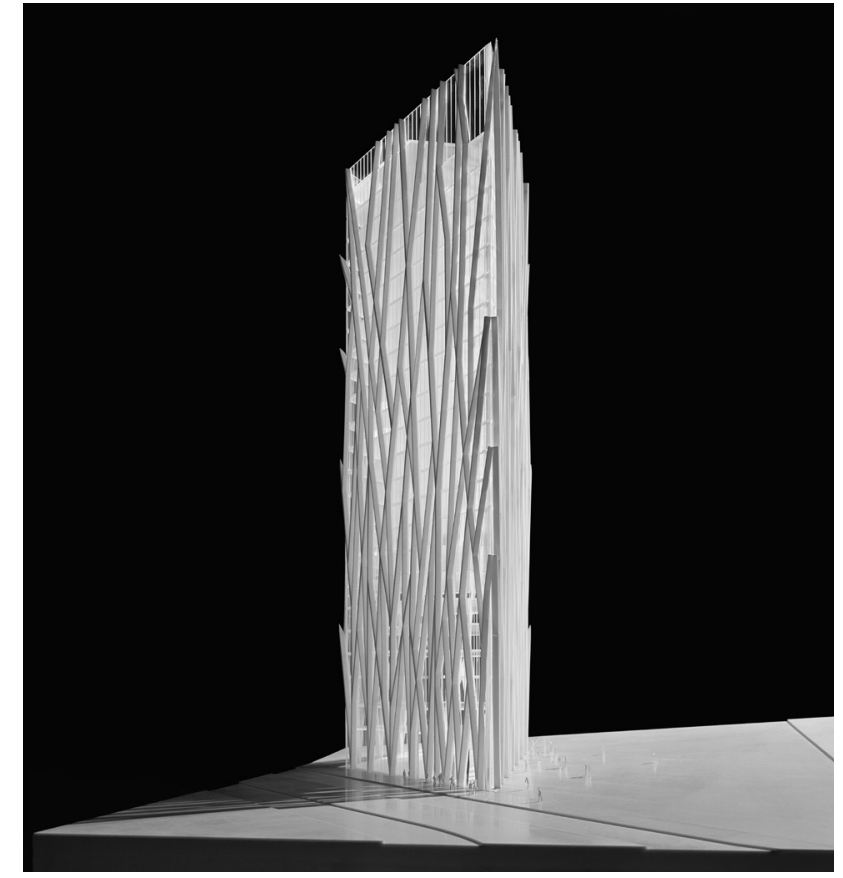

FIG. 1. Maqueta del anteproyecto final. @ A Aleix Bagué

\section{Diagonal ZeroZero: forma y técnica}

\section{Enric Massip-Bosch}

\author{
Recibido 2020.06.01 :.: Aceptado 2020.06.05 \\ DOI: 10.5821/palimpsesto.21.9502 \\ Persona de contacto: emba@emba.cat \\ ORCID: https://orcid.org/0000-0002-6988-9472 \\ Doctor arquitecto por la UPC
}

\section{ABSTRACT}

La fundamentación conceptual de la forma ha sido un tema recurrente en la historia de la arquitectura. Más allá del cariz que en cada momento y desde cada posicionamiento se le quiera dar a esta fundamentación, existe la insoslayable necesidad de construir la arquitectura para que pueda desplegar sus cualidades. La tradición de las escuelas politécnicas combina la reflexión proyectual con la reflexión técnica como uno de los elementos clave para definir la forma arquitectónica. La complejidad de nuestro momento aboca al arquitecto a definir esta forma en diálogo o negociación con otros agentes. Un caso de estudio es la Torre Diagona ZeroZero en Barcelona la cual, a partir de una concepción previa integral de la forma y la técnica del edificio, se desarrolló
en una estrecha colaboración arquitectura-ingeniería.

PALABRAS CLAVE: proyecto; estructura; arquitectura; construcción; colaboración; tipo; ciudad

a cuestión del origen de la forma arquitectónica ha sido recurrente en la historia. Desde los textos vitrubianos hasta los procesos participativos actuales, han sido diversos los puntos de apoyo sobre los que se ha querido sustentar el proyecto y su resultado formal. A veces, con un propósito justificativo y programático que Geoffrey Scott ya denunció como falacias (Scott, 1914), precisamente porque niegan la posibilidad a la arquitectura de ser entendida por sí misma, desde su propia presencia. Sin embargo, justo porque el objetivo último de toda arquitectura es construir esa presencia, cabe seguir preguntándose por la relación entre su forma y la técnica que la posibilita. Esta relación, o bien se piensa desde el proyecto, o se resuelve a pesar del proyecto, pero es insoslayable.

La formación en las escuelas politécnicas se basa en considerar los aspectos técnicos como marco de diseño. La reflexión operativa sobre el tipo y sobre la ciudad es hoy también habitual. Esta nueva tríada (ciudad, tipo y técnica) conforma una base sobre la que construir la idea del proyecto y definir su forma: en su interoperabilidad radica el rol del arquitecto. Pero en el mundo actual, enmarañado en responsabilidades legales y normativas, con una evolución constante de soluciones, métodos y

La forma de Diagonal ZeroZero quedaba así definida en el anteproyecto considerando sus relaciones con la ciudad, con el tipo y con la técnica. Faltaba encontrar los especialistas que, además de hacerla posible, aportaran desde su propia experiencia más profundidad a las ideas iniciales. Queríamos que construir la torre fuera también una oportunidad para los colaboradores habituales de EMBA. Pero no pudimos contar con nuestro experto en estructuras e iniciamos una ronda de entrevistas. La última la tuve con Julio Martínez Calzón. Cuando cogió la imagen de la maqueta y, antes casi de que pudiese explicarle nada, dijo "eso es un disparate", supe que aquél era el ingeniero que me convenía: el conocimiento surge de la fricción, y es más orientadora una actitud escéptica que una condescendiente, porque hoy día cualquier cosa se puede terminar construyendo.

Entre las intuiciones iniciales y el resultado final se desarrolló un diálogo de forma natural, porque ambos compartíamos la voluntad de optimizar la estructura. Aquella fricción a la que me refería, a veces muy intensa, ha dado los frutos esperados. Martínez Calzón ha detallado en otros lugares el proceso de definición constructiva y dimensional del edificio (Martínez Calzón, 2015). Su aportación y la de su equipo en MC2 ha sido insustituible no solo en los aspectos conceptuales o de cálculo, sino que su experiencia resultó decisiva para que la construcción fuese viable en términos económicos y temporales, muy ajustados.

El izado de la estructura hasta los $110 \mathrm{~m}$ de cornisa debía cumplir simultáneamente dos condiciones: realizarse en unos plazos muy cortos y hacerlo con la máxima precisión y calidad final, dado que la estructura es, de hecho, los acabados del edificio. Un ejemplo de esta doble condición es el núcleo central, de hormigón visto. Su construcción requirió un complejo encofrado que fuera al mismo tiempo rápido de subir planta a planta y que diese una calidad pétrea al acabado. Al ser autoportante, permitía construir el tambor central con independencia de los otros trabajos de plantado de la estructura vertical y de formación de la losa de forjado.

Otro ejemplo es la estructura metálica vertical, muy esbelta. Como la definición del muro cortina dependía estrechamente de su geometría, era fundamental tener un gran control de su verticalidad en toda la altura. En esta fase se trabajó veinticuatro horas diarias; dadas las variaciones térmicas entre momentos del día y entre fachadas, esta tarea resultó doblemente complicada. Se resolvió con la fabricación en taller de complicada. Seresovió con la festicación en taller de que eran fáciles de colocar en obra y que dejaban entre sí suficiente margen para absorber diferencias dimensionales.

materiales, el arquitecto debe negociar el proyecto con múltiples especialistas, y conseguir el mejor resultado. Sólo es posible abordar con éxito este proceso complejo desde la capacidad de integrar estos conocimientos parciales en un objetivo que ya los contemple de algún modo en las fases iniciales del proyecto.

La Torre Diagonal ZeroZero en Barcelona (Enric Massip-Bosch_EMBA, 2005-2011) es un ejemplo de colaboración múltiple en un proyecto complejo y significativo en la ciudad, a partir de decisiones arquitectónicas primigenias. Algunas de éstas eran específicas del lugar. Como observa el crítico italiano Alfredo Zappa, más que de landmark se puede hablar de esta torre de $110 \mathrm{~m}$ de altura como marked by land (Zappa, 2012, p. 75) en el sentido que se propone como un edificio contextual a pesar de sus dimensiones y su posición. Esta fue una primera intención: generar un diálogo con la ciudad, de lejos y de cerca; conectar directamente el edificio con el espacio público circundante; abrir el edificio hacia la ciudad y hacia el territorio mediante dos atrios de gran altura situados en la planta baja y en la 17

Otras decisiones concernían cuestiones genéricas, como el tipo edificatorio. En la fase de anteproyecto no había todavía un usuario definido. A partir de un análisis de casos corporativos europeos similares, se adoptaron las decisiones sobre variedad programática, dimensionado general o relaciones entre piezas, de modo que apoyaran las decisiones de índole urbana. Estas opciones tipológicas y urbanas se reforzaron con la definición del sistema constructivo y estructural del edificio. Para obtener la máxima ligereza exterior y la máxima versatilidad interior, optamos por un esquema tube-in-tube modificado. Sin pilares intermedios, la estructura consiste en un núcleo interior de muros de hormigón y en un anillo estructural perimetral de acero. Éste diferencia los elementos de soporte a compresión, muy esbeltos, de los elementos de riostra a esfuerzos horizontales y de torsión, definidos por una celosía estructural exterior. El resultado es una fachada gruesa, protectora y cambiante, que no termina en la lámina invisible del vidrio del muro cortina y que ofrece una experiencia interior rica y matizada.
Al cerrar la fachada con los módulos acristalados, la estructura sufre la presión del viento y es necesario arriostrarla. Se debía por tanto comenzar a montar la celosía exterior a partir de un determinado número de celosía exterior a partir de un determinado número de
plantas, que en la parte baja, la más solicitada, era de cinco, y en la parte alta, de ocho. La colocación de un muro cortina modular como el de Diagonal ZeroZero es muy rápida, pero se tuvo que suspender cerca de un mes debido a problemas de fabricación de la estructura exterior, hasta que pudo seguir montándose la celosía de arriostramiento. El resultado de estos esfuerzos combinados fue que la estructura se completó en ocho meses, a razón de una planta por semana.

Este ha sido un proyecto largo y una obra corta y difícil. Se ha realizado con la implicación de mucha gente compartiendo un objetivo claro pero que se acaba de definir en un proceso abierto. La lección, que no es única de Diagonal ZeroZero pero que ejemplifica diáfanamente, es que todo ello sólo es posible en un contexto de colaboración transdisciplinar honesta y generosa que resuelva la relación entre forma y técnica de un modo alineado para obtener el mejor resultado posible: que la singularidad de su presencia esté al servicio de la ciudad y de sus usuarios; que contribuya, en definitiva, a mejorar la vida de todos.

\section{REFERENCIAS}

Martínez Calzón, Julio (2015). "La estructura portante de Arquitectura 2005-2015, pp. 226-235.

Scott, Geoffrey (1914). The Architecture of Humanism: A Study in the History of Taste, Londres: Constable \& Co.

Zappa, Alfredo (2012). "Diagonal ZeroZero", Casabella, núm. 813, pp. $70-85$.

ENRIC MASSIP-BOSCH es Doctor Arquitecto por la Universidad Politécnica de Catalunya (UPC). 